\title{
Perception of Medical Students Towards COVID-19 Outbreak and Movement Control Order (MCO) in Malaysia and Impact on Education
}

\section{Mogesh Sababathy}

National University of Malaysia, Universiti Kebangsaan Malaysia Medical Center Aida Hani Mohd Kalok

National University of Malaysia, Universiti Kebangsaan Malaysia Medical Center Abdul Muzhill Hannaan Abdul Hafizz

National University of Malaysia, Universiti Kebangsaan Malaysia Medical Center

Shalisah Sharip

National University of Malaysia, Universiti Kebangsaan Malaysia Medical Center

Zulkifli Md Zainuddin

National University of Malaysia, Universiti Kebangsaan Malaysia Medical Center

Mohamad Nasir Shafiee ( $\nabla$ nasirshafiee@ukm.edu.my)

National University of Malaysia, Universiti Kebangsaan Malaysia Medical Center

\section{Research Article}

Keywords: COVID-19, Movement Control Order, medical students, perception

Posted Date: July 8th, 2021

DOI: https://doi.org/10.21203/rs.3.rs-646716/v1

License: (c) (i) This work is licensed under a Creative Commons Attribution 4.0 International License. Read Full License 


\section{Abstract}

Background: A Movement Control Order (MCO) was imposed as a control measure to curb the spread of COVID-19 virus in Malaysia, eventually led to the closing of all public premises including educational institutions nationwide. The purpose of this study is to offer an understanding of undergraduate medical students' perception towards the occurrence of COVID-19 pandemic, the implementation of MCO and their impacts on education.

Methods: A cross-sectional study design was used to collect data from 772 medical students over 2 weeks in September 2020 through an online self-reported survey.

Results: In total, $80 \%$ of the participants were aware about the COVID-19 outbreak ranging from the modes of transmission, global and local scenario of the pandemic, its seriousness and measures to break the chain of transmission.

Conclusions: Majority of them agreed on the implementation of MCO in the country, however it's reported to have caused psychological and physical distress in various degrees. The present finding also provides evidence of a high prevalence of anxiety and worriness in regard to the teaching and learning process during the MCO and agreed that online teaching is not as effective as face-to-face teaching.

\section{Introduction}

An unknown strain of virus named COVID-19 has put the entire world on a global health emergency since its first emergence in late December 2019 when a cluster of unexplained pneumonia was identified in the city of Wuhan, the capital of Hubei, China. Thenceforth, COVID-19 has started to spike greatly in almost every country in the world including Malaysia approaching seventy-two thousand cases with a mortality rate of $0.53 \%$. The World Health Organisation (WHO) and several other public health agencies like the Centre for Disease Control and Prevention (CDC) have stepped forward to collaborate with various diagnostic and research laboratories in efforts to find a solution to this novel disease as well as to continuously providing essential information about COVID-19 to people in order to keep the global community protected and informed.

The Malaysian government has since taken drastic actions as preventive and containment measures to curb the spread of the virus. This includes mass screenings, media campaigns, travel restrictions as well as closure of all government and private premises except for essential services following the implementation of a nationwide Movement Control Order (MCO) by the Federal Government of Malaysia starting March 18, 2020. Subsequently as the spread of the virus in the country becomes more controlled, different levels of restrictions were introduced including the Conditional Movement Control Order (CMCO) and Enhanced Movement Control Oder (EMCO) in order to continue to break the chain of transmission by cluster-specific and close contact tracing which was as well heavily supported by statistics of daily counts of infected individuals and the infectivity rate of COVID-19 or $R_{0}$. $R_{0}$ is often referred to as a 
reproductive number and commonly used to indicate the infectiousness of the virus as well as to predict the transmission of an infectious disease.

Scientific evidences from all around the world has been vastly showing how COVID-19 has caused devastating effects not only to the global economy but also the livelihood and mental health of people worldwide(1-4). The impact has also been substantially seen among university students causing physical and psychological distress that leads to symptoms of depression, anxiety and even suicidal thoughts(5-7). A recent study demonstrated at least $29.8 \%$ out of 983 Malaysian students experienced mild to extremely severe level of anxiety during the MCO period(8) meanwhile another study with a sample size of 7143 comprising of college students in China recorded $24.9 \%$ of the population experienced some level of anxiety during the pandemic(9).

Researches around students' perspectives during COVID-19 on academics in terms of adapting to virtual learning, financial and resources constraints as well as their worriness towards the academic performance is still quite limited which we believe it needs to be just as equally addressed to ensure that the quality of the education will never be compromised. Thus, medical students specifically those in the clinical years required to be attached to hospitals for training was brought to our attention whom are highly vulnerable to contracting the virus and eventually being either symptomatic or asymptomatic carriers of COVID-19 considering their rate of exposure to the disease is relatively higher(10). The current study is aimed to investigate perception of undergraduate medical students towards the occurrence of COVID-19 pandemic and its impact on their education. As evidenced worldwide, we hypothesize that the emergence of COVID-19 in Malaysia would be much likely to have affected students not only in terms of changes in their lifestyle but also their mental and physical well-being that could concomitantly influence their learning negatively.

\section{Methods}

\section{Study design, participants, and data collection}

This cross-sectional study administered an anonymous self-report questionnaire survey involving students from the Faculty of Medicine at the National University of Malaysia, Kuala Lumpur. Data were collected in the fourth and fifth weeks of MCO in September 2020. The respondents consisted of clinical undergraduate students from several courses including medicine, nursing, and emergency medicine. A total of 772 responses were collected from students who agreed to participate and answered all the questions and submitted via Google Form over a two-weeks period.

\section{Questionnaire design}

A questionnaire was designed consisting of four categories: socio-demographic information (Information), awareness of COVID-19 (Awareness), opinion about the implementation of MCO and its effects on self and academics (Perception) and readiness of online and face-to-face teaching (Readiness). The questionnaire was designed in English with Malay translation. Socio-demographic 
information included age, ethnicity, gender, marital status, course (i.e., "medicine, nursing, or emergency medicine"), year of study, financial source, source of support, and COVID-19 status. Awareness comprises of mode of transmission of COVID-19, the seriousness of the infection on the global and local scale, methods of testing, treatment and etcetera using a 3-point Likert scales (less aware, neutral and highly aware).

As for the opinion about MCO and its effects on self and academics were designed as 5-point Likert scales ranging from "strongly disagree, disagree, neural, agree and strongly agree". Lastly, the readiness of online and face-to-face teaching was broken into two sub-sections. The first sub-section was constructed to identify the availability of devices and internet services for online learning among the students (i.e., "online learning platforms, types and number of devices and internet speed") and the second sub-section was to assess their opinion about online teaching and learning with three questions as described in Table 7.

\section{Statistical analysis}

The study data was analysed using The Statistical Package for Social Sciences; IBM SPSS Statistics for Windows, version 24 (IBM Corp., Armonk, NY, USA). Histogram with error bars and other basic descriptive statistics including the mean and frequencies were obtained. Normalization of scores were carried out for the effects of $\mathrm{MCO}$ using the Kolmogorov-Smirnov test(11). A reliability test, the Cronbach's Alpha test was used to measure the internal consistency for the $\mathrm{MCO}$ effects gave us a value of 0.862 , indicating a good reliability meanwhile the difference between groups for demographic variables and social support were assessed using t-tests and one-way ANOVA. Meanwhile, the Mann-Whitney test was used to investigate whether factors including age groups, gender, ethnicity, course, year of study, social support, electronic devices, information source of teaching platform have impacts on the perception of students towards MCO, learning support and learning anxiety. Significance of results was declared when the Pvalue is less than $0.05(P<0.05)$.

\section{Results}

\section{Demographics}

Out of 993 undergraduates who received the survey form, 772 students completed the survey making the response rate $77.7 \%$, as presented in Table 1 . The survey was conducted in the fourth and fifth weeks of the MCO month in April 2020. Mean age of the students were $22.6( \pm 2.53)$ and majority of them were female, $553(71.6 \%)$. Most of the participants were Malay (60.9\%), followed by Indian (17.4\%) and Chinese (15.2\%). Only $1.8 \%$ of them were married, while the rest were single (98.2\%). $81.2 \%$ of the participants were in the Medical degree course followed by Nursing and Emergency Medicine program, $13.5 \%$ and $5.3 \%$ respectively which was proportionate to the enrolment of undergraduate students in our faculty. Their study years were almost equally distributed from first to fifth year. In addition, most of them received scholarship or education funds (81.6\%), and the rest depended on parental support, meanwhile only $3 \%$ worked on a part-time basis. The study revealed that most participants received strong social 
and/or financial support from their family or relatives during the MCO. More than half of them received at least one source of support, including friends, course mates and university or government agencies. None of the participants involved in this study were tested positive for COVID-19.

\section{Level of awareness and knowledge of COVID-19}

Based on our results in Table 2, more than $80 \%$ of the students were found to be aware on the mode of COVID-19 transmission, the seriousness of the virus that is effecting the global population, the methods of testing, unavailability of vaccines, measures to reduce transmission, daily trend of the infection, local scenario of this outbreak and the involvement of their training hospital in treating COVID-19 positive patients.

\section{General opinion on movement control order (MCO), and its effects onto them.}

The present study as described in Table 3 and Table 4 revealed that $87 \%$ of the respondents had positive response on the necessity of implementing the MCO in the country, as to prevent transmission within the community, meanwhile $7 \%$ reported the contrary. One the other hand, although $27.6 \%, 36 \%$ and $44.6 \%$ participants were reported to be experiencing stress, depression and anxious, respectively when assessed using DASS21 questionnaires (data not shown in table), they strongly agree to prolong MCO if necessary. Besides, most of them were happy (agree or strongly agree) with the enforcement by the government authority and responded to have been receiving adequate update and information nationally. Interestingly $26.9 \%$ of them perceived MCO did not disrupt their daily life and almost half (43.4\%) reported that their physical well-being was not affected. A total of $380(49.2 \%)$ disagreed or strongly disagreed that MCO had caused their mental or psychological well-being. However, between $13.7 \%$ to $18 \%$ neither agreed nor disagreed that MCO has affected their mental and physical well-being. Furthermore, a total of $81.8 \%$ of the participants reported that they had enough social and psychological support during the course of the pandemic.

The reliability of the questionnaire was checked using the Cronbach's alpha test that gave us a value of 0.862 which indicated a good reliability and the BRS score, in addition, revealed that $165(21.4 \%)$ participant had low resilience (score: 1.00-2.99). With regards to the awareness of the MCO implication to their study, more than $90 \%$ agreed or strongly agreed that it will affect their study and they were appropriately informed regarding the change in the teaching schedule. Nevertheless, $81 \%$ of the participants were reported to have been experiencing anxiety mostly due to the uncertainties of their posting schedules. Unexpectedly, only $12 \%$ of the students seemed to be unworried about failing their examinations though there were limitations to teaching and learning process to a certain extent during the MCO. A total of 44 participants $(5.7 \%)$ had either strongly disagreed or disagreed on whether they were aware of the availability of online teaching facility. Even though most of them were aware but about $38.2 \%$ of them strongly disagreed on the equality of quality of online learning method in comparison to conventional face-to-face classes.

\section{Readiness of online teaching and learning method}


The readiness of the participating students in the current study on online teaching and learning method was also assessed by surveying their possession over personal electronic devices (desktop, laptop, smartphone and tablet) as described in Table 5 and Table 6 . Intriguingly, 62 (8\%) of them did not own any of these devices. In regard to the internet speed for those who possess at least 1 electronic device, 55 (7.1\%) had extremely slow connectivity with less than 1 Megabits per second (Mbps). Almost all respondents were aware of various platforms available for online teaching and learning, mainly the UKM Folio platform (designed by university teaching coordinator) followed by $86.7 \%$ and Zoom (92.2\%). Entering the second week of MCO, almost all (99.4\%) started utilizing online platforms with their lecturers or tutors. Only $5(0.6 \%)$ reported to have not engaged in online sessions at all. Those who had been using the online learning platforms however, found it very poor or not very informative by 133 persons (17.2\%), while on the other hand, only about $19.7 \%$ of the students were very happy with online learning, and majority $74.4 \%$ doing this form of learning as there are no other options.

\section{Students' perception towards MCO, learning support and learning anxiety}

In an effort to further investigate whether factors including age groups, gender, ethnicity, course, year of study, social support, electronic devices, information source and teaching platform have impacts on the perception of students towards MCO, learning support and learning anxiety and was analysed using the Mann-Whitney test as portrayed in Table 7. Results where $p<0.005$ were considered to be statistically significant. Generally, the results showed that the students' perception towards MCO (8.8\%), learning support (11.6\%) and learning anxiety $(6.2 \%)$ were considerably low. There was a significant effect of age on all three survey constructs: MCO perception, learning support, and learning anxiety $(p<0.05)$. Gender, and ethnicity only demonstrated significant effect on MCO perception and learning anxiety meanwhile, information source, and teaching platform showed significant effect on MCO perception and learning support.

On the other hand, course, social support, and electronic devices expressed significant effect only on learning support and year of study affected only learning anxiety. However, course, year of study, social support, and electronic devices demonstrated no major effects on MCO perception ( $p>0.05)$. Gender, ethnicity and year of study exhibited no significant effects on learning support and course, social support, electronic devices, information source, and teaching platform showed no significant effects on learning anxiety.

\section{Discussion}

The COVID-19 outbreak does not only cause devastating effects on the economy, social and mental wellbeing of the global community but has also led to a dramatic effect on the education system as it has been continuously reported worldwide. Various issues with respect to the quality of the global education during the pandemic has been vastly addressed especially medical education whereby the most affected group are those in the clinical clerkship year. Issues including the uncertain safety of the students and 
patients, lacking of hands on clinical exposure, and most importantly leaving the standards and competencies of medical education at stake are largely discussed.

Thus, we took the initiative to conduct a critical survey involving current undergraduate medical students to assess their overall perception of the current crisis as well as to evaluate their mental and physical well-being during the MCO. Data from our Undergraduate Secretariat revealed that there were a total of 744, 136 and 47 students in Medicine, Nursing and Emergency Medicine Programs, respectively, and of that, the response rate of this survey was $83.3 \%$, which met the standards of survey reliability(12). Enrolment into degree programs generally starts at the age of 19 in Malaysia, and in this survey the mean age was $22.6 \pm 2.53$ years. The ethnicity and gender were in due proportion to the participants' distribution.

The findings of the present study revealed that there was a highly significant difference $(P<0.001)$ in the effects of MCO between gender, in which, interestingly, male students were found to be experiencing more negative impacts in their daily life, mental and physical wellbeing than the female counterpart. This could possibly due to their restricted movements during the course of MCO especially for those who were actively involved in physical and outdoor activities before the pandemic. A study that was conducted in Bangladesh, correlates with this study which reported that male university students showed higher depressive symptoms than the female students(6).

In contrast, a survey among 1257 healthcare workers in 34 different hospitals across China revealed a Generalized Anxiety Disorder scale scores among men was significantly lower than women(13). Another study involving university students in Malaysia also reported that the female students were found to experience higher levels of anxiety and stress as they have lover tolerance threshold in handling and managing difficult and pressured times in relative to the males(8).

As mental/psychological state of a person is seen as an utmost important aspect to be taken a lot of care of during any crises, this study has found that the presence of various sources of supports around the students had significantly improved their mental health during the pandemic. Although majority of the students agreed that the implementation of MCO has disrupted their daily life, all of them had at least 1 source of support accounting their families to be the most common source of support. Most of the students in our cohort also mentioned that they had enough social and psychological support from various sources during the pandemic. This explains the low number of students who find that MCO did not affect their physical and mental well-being. A study involving college students at the United States revealed that the participants found interacting with family members and friends, engaging with professional counselling services via therapists and mental health mobile applications were helpful in coping with stress and anxiety during COVID-19(7).

Furthermore, the Centers for Disease Control and Prevention(14) had also suggested a list of ways to cope with possible psychological impacts including to stay connected with families, friends and relatives, get in touch with faith or social support groups or organisations as well as to limit oneself from watching, reading or listening to the news that may cause distress, worry or anxiety. Most of the students 
participated in this study were also found to be well supported financially by some form of aids including scholarships, loans and part-time work incomes. Thus, the students reported that MCO in whole did not cause them a financial upheaval. Not to forget that the government also provided special allowances for university students during the $\mathrm{MCO}$ as part of national economic stimulus packages which was very well welcomed by Malaysian students that helped to reduce their financial burdens surviving through the crisis.

Public awareness has been particularly given a major attention around the world since the start of the COVID-19 outbreak. This includes the dissemination of guidelines and information on preventive measures to curb the spread of the virus. As this virus primarily targets respiratory system, the World Health Organisation (WHO) and Centers for Disease Control and Prevention (CDC) recommends the public to always practise respiratory hygiene and frequent use of hand sanitizer. The Malaysian government also has since introduced and enforced Standard Operating Procedures (SOP) as a set of guidelines to break the chain of transmission of the virus in the country and as well monitors and issues penalties to individuals who violate them to ensure public adherence.

In this study, in whole, the participants showed a strong level of knowledge and awareness about the outbreak and the implementation of the MCO. This is possibly due to the active updates and information sharing about the virus and SOPs throughout the lockdown period by the government through various online and offline platforms mostly through internet and social media followed by television channels, radio, newspapers and scientific journals(15). Though a relatively smaller number of students in the present study were reported to have been mentally affected during the $\mathrm{MCO}$, they were highly supportive and satisfied of the measures taken and the amount of information disseminated by the government. Half of them felt that the movement restriction did not affect their physical and mental well-being which resulted them in positively responding and being adherent to the recommendations and guidelines by the government indicating a good level of resilience.

The students were mostly aware and appropriately informed on the implications of MCO on their studies and the changes in their class and posting schedules as well as the introduction and the availability of elearning platforms during the whole lockdown period. Nevertheless, a large number of them reported that they were worried about failing their examinations and getting less clinical attachments for practical lessons. More than half of them also felt that online teaching does not have the same quality as the traditional classroom learning which has direct or face-to-face student-lecturer engagement. These responses are coherent to similar studies all around the world, for instance as described by Dost et al.(16) also involving medical students who do not find online teaching as effective as face-to-face teaching for several reasons. It includes limited opportunity to ask questions and do not find as engaging and enjoyable despite the fact that online teaching has multiple advantages like saves cost and time on travelling and provides more flexibility and comfort to students.

Certainly, the pandemic has also forced education institutions in many parts of the world to abruptly shift to distance learning or e-learning and use online communication and education platforms to ensure that 
the education process goes on as usual. Despite the facts that it assured the continuity of teaching and learning process and other advantages that were evidenced to facilitate some benefits during the pandemic as widely described(17-19), the unforeseen changes however, had stirred up some challenges. This includes limited accessibility to electronic devices and internet facilities, disrupted social interactions, difficulties in understanding instructional goals, digital illiteracy among students and lecturers as well as limitations of the technology itself(20-22).

In regards to medical students, the clinical students especially are most likely to be heavily affected by the sudden shift as during their clerkship years they would have to be physically involved and gain more practical and hands-on clinical experiences which they would not be getting from online learning. In this study, we were able to record the students' responses particularly on their overall readiness towards elearning teaching and learning approach. Majority of the participating students possessed at least 1 electronic device and were aware of online learning platforms that were used as an alternative method to traditional classroom learning.

However, there was a small number of students who reported to not own any personal devices and to have very bad internet connectivity which eventually would have disrupted their learning process in terms of catching up with the syllabus taught, to complete as well as to handing in tasks like quizzes and assignments in time. This correlated with a study conducted in Vietnam where the students described that poor ICT infrastructure, internet speed and access has badly impacted their online learning experience(23). Similarly, technological difficulties have been identified as one of the major reasons to dissatisfaction of online learning by a group of students in Lebanon which has contributed to delay in information acquisition, limited access to educational resources and disruption in student-lecturer interaction which also includes not being able to attend classes and online exams(24).

In whole, it was found that most of the students were ready and accept online learning if there is no any other choice but it is important to also acknowledge the students who do not find it very useful and instead provide them alternative methods of learning including by conducting extra classes, providing additional notes and exercises and arranging private tutoring to students who may need extra support and attention. On that note, Chakraborty et al.(25) suggested that self-reflection and periodic assessment in the course of online learning can also be conducted besides developing creative and interactive lesson plans and lecture delivering methods to increase student involvements and enhance the quality of knowledge acquisition.

When it comes to medical students especially those who are in their clerkship years, it is important that they are exposed to practical lessons and real world cases and unfortunately it has been vastly reported that online learning has been mostly dissatisfying. In regards to that, Bączek et al.(19) suggested the use of remote standardized patients (RSPs) whereby the students will get to interact with their patients in realtime via video conferencing and previous literatures also suggest several other methods used by medical schools worldwide including the use of video tutorials, polls, quizzes, question and answer sessions and games to increase their learning experience. 


\section{Conclusion}

The MCO was enforced nationwide in March 2020 in light to breaking the chain of COVID-19 transmission but it has also since presented varied perceptions and behavioural changes affecting Malaysians of various age groups mentally, emotionally and physically. Nevertheless, the present study demonstrated a high level of acceptance among medical students towards the implementation of MCO by the Malaysian government considering the sufficiency of updates and public health information given to them on a regular basis. It is also fair to conclude from the results of our study that MCO has not majorly affected physical and psychological well-being of the students, largely due to getting adequate social and financial support from their families and/or relatives. However, a large number of them reported to be anxious and worried about their academic progress and performance during the restriction period especially considering the changes in the mode of teaching from face-to-face classes to online classes, changes in class schedules and lacking in hands-on learning that is usually carried out through practical lessons and clinical attachments. Movement restriction has greatly taken a toll on students on varying degree as reported by other researchers. We, therefore, through this study intend to inform governmental and private organizations to "step in" and incorporate academic and psychological intervention along with the fight against COVID-19.

\section{Declarations}

\section{Ethics approval and consent to participate}

Ethical approval was obtained from the Universiti Kebangsaan Malaysia (UKM) Medical Research and Ethics Committee (Research Code: JEP-2020-035).

\section{Consent for publication}

Not applicable.

\section{Availability of data and material}

All data concerning selection process generated or analyzed during this study are included in this published article and its supplementary information files. The datasets used and/or analyzed during the current study are available from the corresponding author on reasonable request

(interview and observation data are not available for release beyond the research group as per ethical clearance stipulations to protect the respondent's anonymity).

\section{Competing interest}

The authors declare that they have no competing interests.

\section{Funding}


None.

\section{Authors' contribution}

M.N.S.: Conceptualization, A.M.H.A.H.: Data curation, M.N.S., A.M.H.A.H., M.S., A.H.M.K., S.S., Z.M.Z.: Formal analysis, M.N.S., A.M.H.A.H., M.S.: Methodology, M.N.S.: Project administration, M.N.S.:

Supervision, M.S., M.N.S.: Writing-original draft, M.S., M.N.S.: Writing-review \& editing. All authors have read and agreed to the final draft of the manuscript.

\section{Acknowledgement}

The authors would like to thank the participating students for their time and input in this study.

\section{Ethics}

Ethical approval was obtained from the Universiti Kebangsaan Malaysia (UKM) Medical Research and Ethics Committee (Research Code: JEP-2020-035). Informed consent was obtained from each participant on the first page of the questionnaire.

\section{References}

1. Mohamed-Azzam Zakout Y, Saud Alreshidi F, Mustafa Elsaid R, Gadelkarim Ahmed H, 1 Department of Pathology, College of Medicine, University of Hail, Hail, Kingdom of Saudi Arabia, 2 Department of Family and Community Medicine, College of Medicine, University of Hail, Hail, Kingdom of Saudi Arabia, et al. The magnitude of COVID-19 related stress, anxiety and depression associated with intense mass media coverage in Saudi Arabi. AIMS Public Health. 2020;7(3):664-78.

2. Shi L, Lu Z-A, Que J-Y, Huang X-L, Liu L, Ran M-S, et al. Prevalence of and Risk Factors Associated With Mental Health Symptoms Among the General Population in China During the Coronavirus Disease 2019 Pandemic. JAMA Netw Open. 2020 Jul 1;3(7):e2014053.

3. Mhlanga D, Ndhlovu E. Socio-economic Implications of the COVID-19 Pandemic on Smallholder Livelihoods in Zimbabwe [Internet]. SOCIAL SCIENCES; 2020 Apr [cited 2021 Jun 2]. Available from: https://www.preprints.org/manuscript/202004.0219/v1

4. Martin A, Markhvida M, Hallegatte S, Walsh B. Socio-Economic Impacts of COVID-19 on Household Consumption and Poverty. Econ Disasters Clim Change. 2020 Oct;4(3):453-79.

5. Kecojevic A, Basch CH, Sullivan M, Davi NK. The impact of the COVID-19 epidemic on mental health of undergraduate students in New Jersey, cross-sectional study. Vickers K, editor. PLOS ONE. 2020 Sep 30;15(9):e0239696.

6. Islam MdA, Barna SD, Raihan H, Khan MdNA, Hossain MdT. Depression and anxiety among university students during the COVID-19 pandemic in Bangladesh: A web-based cross-sectional survey. Pakpour AH, 
editor. PLOS ONE. 2020 Aug 26;15(8):e0238162.

7. Son C, Hegde S, Smith A, Wang X, Sasangohar F. Effects of COVID-19 on College Students' Mental Health in the United States: Interview Survey Study. J Med Internet Res [Internet]. 2020 Sep 3 [cited 2021 Jun 3];22(9). Available from: https://www.ncbi.nlm.nih.gov/pmc/articles/PMC7473764/

8. Sundarasen S, Chinna K, Kamaludin K, Nurunnabi M, Baloch GM, Khoshaim HB, et al. Psychological Impact of COVID-19 and Lockdown among University Students in Malaysia: Implications and Policy Recommendations. Int J Environ Res Public Health. 2020 Aug 27;17(17):6206.

9. Cao W, Fang Z, Hou G, Han M, Xu X, Dong J, et al. The psychological impact of the COVID-19 epidemic on college students in China. Psychiatry Res. 2020 May;287:112934.

10. Kalok A, Sharip S, Abdul Hafizz AM, Zainuddin ZM, Shafiee MN. The Psychological Impact of Movement Restriction during the COVID-19 Outbreak on Clinical Undergraduates: A Cross-Sectional Study. Int J Environ Res Public Health. 2020 Nov 17;17(22):8522.

11. Pappa S, Ntella V, Giannakas T, Giannakoulis VG, Papoutsi E, Katsaounou P. Prevalence of depression, anxiety, and insomnia among healthcare workers during the COVID-19 pandemic: A systematic review and meta-analysis. Brain Behav Immun. 2020 Aug;88:901-7.

12. Fincham JE. Response Rates and Responsiveness for Surveys, Standards, and the Journal. Am J Pharm Educ. 2008 Sep;72(2):43.

13. Lai J, Ma S, Wang Y, Cai Z, Hu J, Wei N, et al. Factors Associated With Mental Health Outcomes Among Health Care Workers Exposed to Coronavirus Disease 2019. JAMA Netw Open. 2020 Mar 23;3(3):e203976.

14. Centers for Disease Control and Prevention. Daily Life Coping Managing Stress Anxiety [Internet]. [cited 2021 Feb 14]. Available from: https://www.cdc.gov/coronavirus/2019-ncov/daily-lifecoping/managing-stress-anxiety.html

15. Hasan H, Raigangar V, Osaili T, Neinavaei NE, Olaimat AN, Aolymat I. A Cross-Sectional Study on University Students' Knowledge, Attitudes, and Practices Toward COVID-19 in the United Arab Emirates. Am J Trop Med Hyg. 2021 Jan 6;104(1):75-84.

16. Dost S, Hossain A, Shehab M, Abdelwahed A, Al-Nusair L. Perceptions of medical students towards online teaching during the COVID-19 pandemic: a national cross-sectional survey of 2721 UK medical students. BMJ Open. 2020 Nov;10(11):e042378.

17. Gonzalez T, de la Rubia MA, Hincz KP, Comas-Lopez M, Subirats L, Fort S, et al. Influence of COVID-19 confinement on students' performance in higher education. Xie H, editor. PLOS ONE. 2020 Oct 9;15(10):e0239490. 
18. Mukhtar K, Javed K, Arooj M, Sethi A. Advantages, Limitations and Recommendations for online learning during COVID-19 pandemic era. Pak J Med Sci [Internet]. 2020 May 18 [cited 2021 Jun 2];36(COVID19-S4). Available from: http://pjms.org.pk/index.php/pjms/article/view/2785

19. Bączek M, Zagańczyk-Bączek M, Szpringer M, Jaroszyński A, Wożakowska-Kapłon B. Students' perception of online learning during the COVID-19 pandemic: A survey study of Polish medical students. Medicine (Baltimore). 2021 Feb 19;100(7):e24821.

20. Amir LR, Tanti I, Maharani DA, Wimardhani YS, Julia V, Sulijaya B, et al. Student perspective of classroom and distance learning during COVID-19 pandemic in the undergraduate dental study program Universitas Indonesia. BMC Med Educ. 2020 Dec;20(1):392.

21. Dhawan S. Online Learning: A Panacea in the Time of COVID-19 Crisis. J Educ Technol Syst. 2020 Sep;49(1):5-22.

22. Selvanathan M, Hussin NAM, Azazi NAN. Students learning experiences during COVID-19: Work from home period in Malaysian Higher Learning Institutions. Teach Public Adm. 2020 Dec 6;014473942097790.

23. Maheshwari G. Factors affecting students' intentions to undertake online learning: an empirical study in Vietnam. Educ Inf Technol [Internet]. 2021 Mar 4 [cited 2021 Jun 2]; Available from: http://link.springer.com/10.1007/s10639-021-10465-8

24. Fawaz M, Samaha A. E-learning: Depression, anxiety, and stress symptomatology among Lebanese university students during COVID-19 quarantine. Nurs Forum (Auckl). 2021 Jan;56(1):52-7.

25. Chakraborty P, Mittal P, Gupta MS, Yadav S, Arora A. Opinion of students on online education during the COVID -19 pandemic. Hum Behav Emerg Technol. 2020 Dec 17;hbe2.240.

\section{Tables}

Due to technical limitations, table 1-7 is only available as a download in the Supplemental Files section.

\section{Supplementary Files}

This is a list of supplementary files associated with this preprint. Click to download.

- Tables21.6ManuscriptMCO.pdf 